\title{
Hubungan Asuhan Antenatal dengan Preeklampsia di RSUP M. Djamil Padang periode 1 Januari 2013 - 31 Desember 2013
}

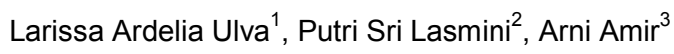

\begin{abstract}
Abstrak
Preeklampsia adalah sindrom spesifik pada kehamilan yang menyebabkan disfungsi organ serta ditandai dengan terjadinya peningkatan tekanan darah dan ditemukannya proteinuria. Preeklampsia ringan yang tidak dikontrol dengan baik melalui asuhan antenatal dapat berkembang menjadi preeklampsia berat. Asuhan antenatal merupakan asuhan yang diajurkan kepada wanita hamil untuk mencegah komplikasi dan menurunkan insiden perinatal dan maternal morbiditas/mortalitas. Asuhan antenatal sebaiknya dilakukan secara berkualitas dengan kuantitas yang sesuai. Kualitas asuhan antenatal ialah kemampuan tenaga kesehatan untuk melakukan konseling dan penyediaan layanan selama kehamilan. Tujuan penelitian ini adalah menentukan hubungan antara kualitas asuhan antenatal dan preeklampsia. Penelitian ini adalah deskriptif analitik menggunakan desain cross sectional dengan jumlah sampel sebanyak 33 orang pasien preeklampsia yang melahirkan di RSUP Dr. M. Djamil periode 1 Januari 2013 sampai 31 Desember 2013. Data dikumpulkan melalui catatan rekam medik yang kemudian di analisis melalui uji chi-square dengan derajat kepercayaan $95 \%(0,05)$. Berdasarkan hasil penelitian didapatkan insiden preeklampsia pada ibu melahirkan sebanyak $13,6 \%$. Hasil uji statistik chi-square menunjukkan tidak ada hubungan antara kualitas asuhan antenatal dan preeklampsia $(p=0,106)$. Simpulan penelitian ini adalah tidak terdapat hubungan yang bermakna antara asuhan antenatal dengan preeklampsia.
\end{abstract}

Kata kunci: asuhan antenatal, kehamilan, preeklampsia

\section{Abstract}

Preeclampsia is a specific syndrome in pregnancy that cause organ dysfunction associated with increasing blood pressure and proteinuria. Mild preeclampsia which is not controlled well through antenatal care can develop into severe preeclampsia. Antenatal care is recommended for pregnant women to prevent complication and decrease the incident of perinatal and maternal morbidity/mortality. Antenatal care quality is the ability of health care personnel to do counseling and provide health service during pregnancy. This objective of this study was to determine the relationship between antenatal care quality and preeclampsia. This was a descriptive analytic study using cross sectional design with 33 preeclampsia patient who give birth at RSUP M. Djamil periode January 1st - December 31st 2013 as the sample. The data was collected through the medical record that analyzed using chi-square test with $95 \%$ confidential interval. The result was the incident of preeclampsia is $13,6 \%$. The results of chi square statistical test showed that antenatal care quality was not related on preeclampsia $(p=0,106)$. The conclusion is no significant relationship between antenatal care and preeclampsia.

Keywords: antenatal care, pregnancy, preeclampsia

Affiliasi penulis: 1. Prodi Profesi Dokter FK Unand (Fakultas Kedokteran Universitas Andalas Padang). 2. Bagian Obstetri dan Ginekologi FK Unand. 3. Bagian Biologi FK Unand

Korespondensi: Larissa Ardelia Ulva, Email:

larissaardelia@yahoo.com, Telp: 085374726236

\section{PENDAHULUAN}

Preeklampsia adalah sindrom spesifik pada kehamilan yang menyebabkan disfungsi organ serta ditandai dengan terjadinya peningkatan tekanan darah dan ditemukannya proteinuria. Preeklampsia biasanya 
terjadi pada kehamilan diatas 20 minggu. Angka kejadian preeklampsia di RSUP M. Djamil tahun 2012 terdapat 10,3\% kasus sedangkan pada tahun 2013 terdapat $13,6 \%{ }^{1,2,3}$

Berdasarkan klasifikasi menurut derajat, preeklampsia dibagi menjadi dua yaitu preeklampsia ringan dan preeklampsia berat. Preeklampsia ringan ditandai dengan tekanan darah < 160/110 dan proteinuria <+2, sedangkan preeklampsia berat ditandai dengan tekanan darah $>160 / 110$ dan proteinuria $\geq+3$. Preeklampsia ringan yang tidak dikontrol dengan baik melalui asuhan antenatal dapat berkembang menjadi preeklampsia berat. Preeklampsia berat dapat berdampak pada fetal outcome, seperti Berat Badan Lahir Rendah (BBLR) hingga kematian ibu dan janin. ${ }^{4}$

Asuhan antenatal (kunjungan kehamilan) perawatan antepartum komprehensif yang melibatkan pendekatan terpadu perawatan medis dan dukungan psikososial yang secara optimal dimulai sebelum konsepsi dan meluas ke periode antepartum. Perawatan komprehensif ini mencakup penilaian prakonsepsi, kunjungan awal perawatan kehamilan, serta tindak lanjut selama kunjungan antenatal berikutnya. Tujuan utama tindakan ini ialah menentukan status kesehatan ibu dan janin, menentukan usia gestasi janin, dan memulai rencana untuk melanjutkan perawatan obstetric. ${ }^{1}$

Asuhan antenatal sebaiknya dilakukan secara berkualitas dengan kuantitas yang sesuai. Kualitas asuhan antenatal ialah kemampuan tenaga kesehatan untuk melakukan konseling dan penyediaan layanan selama kehamilan. Dalam kualitas asuhan antenatal yang paling penting ialah tenaga kesehatan dapat mendeteksi faktor risiko pada kunjungan awal serta melakukan pengamatan pada kunjungan berikutnya. Sedangkan kuantitas asuhan antenatal merupakan jumlah kunjungan asuhan antenatal yang dilakukan oleh wanita selama kehamilan dimulai dari trimester pertama hingga trimester ketiga. ${ }^{5}$

Di Indonesia asuhan antenatal biasanya dilakukan sebanyak empat kali kunjungan. Kunjungan dimulai dari trimester pertama sebanyaksatu kali, dilanjutkan pada trimester kedua sebanyak satu kali, dan pada trimester ketiga sebanyak dua kali. Wanita yang tidak memiliki komplikasi dapat melakukan kunjungan minimal, sedangkan pada kehamilan dengan komplikasi seperti preeklampsia, asuhan antenatal sebaiknya dilakukan kunjungan tambahan. Tidak ada jumlah yang pasti, tetapi sebaiknya dilakukan lebih dari tujuh kali kunjungan. ${ }^{6,7}$

Kehamilan berisiko tinggi seperti preeklampsia harus menjalankan asuhan antenatal secara komprehensif, terkoordinasi, berkelanjutan, serta pemeriksaan yang berbasis rumah sakit untuk mengurangi kemungkinan memburuknya komplikasi pada saat kelahiran. ${ }^{8}$

Tujuan umum penelitian ini ialah mengetahui hubungan asuhan antenatal dengan preeklampsia di RSUP M. Djamil Padang periode 1 Januari 2013 - 31 Desember 2013. Tujuan khusus penelitian ini ialah (1) mengetahui kualitas asuhan antenatal penderita preeklampsia yang melahirkan di RSUP M. Djamil Padang periode 1 Januari 2013 - 31 Desember 2013, (2) mengetahui kuantitas asuhan antenatal penderita preeklampsia yang melahirkan di RSUP M. Djamil Padang periode 1 Januari 2013 - 31 Desember 2013, (3) mengetahui tenaga kesehatan yang melakukan asuhan antenatal pada penderita preeklampsia yang melahirkan di RSUP M. Djamil Padang 1 Januari 2013 sampai 31 Desember 2013.

\section{METODE}

Penelitian ini dilakukan di Bagian Rekam Medik RS Dr. M. Djamil Padang dari April 2014 sampai Juni 2014. Sampel adalah data ibu hamil dengan preeklampsia yang melahirkan di RSUP M. Djamil Padang periode 1 Januari 2013 sampai 31 Desember 2013 dengan kelengkapan data rekam medik yang dilanjutkan dengan wawancara asuhan antenatal. Pengambilan sampel menggunakan teknik total sampling.

\section{HASIL}

Berdasarkan penelitian yang telah dilakukan didapatkan 233 pasien preeklampsia (13,6\%) dari 1708 kelahiran. Subjek penelitian yang memenuhi kriteria adalah sebanyak 33 pasien, dimana terdapat 21 orang preeklampsia berat (64\%) dan 12 orang preeklampsia ringan (36\%) dengan karakteristik sebagai berikut. 
Tabel 1. Distribusi frekuensi karakteristik pasien preeklampsia

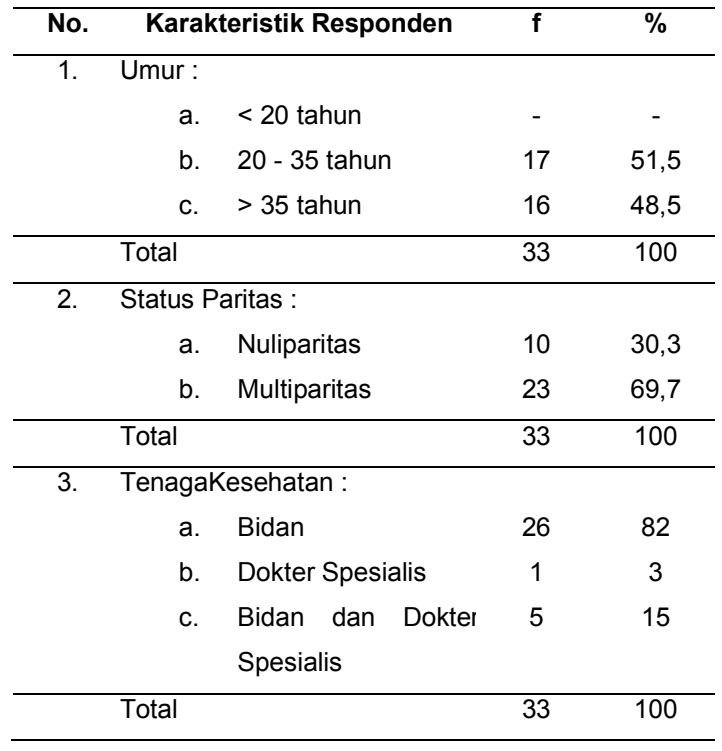

Tabel 1 menunjukkan distribusi frekuensi penderita preeklampsia berdasarkan kelompok umur, maka terbanyak pada umur 20 - 35 tahun yaitu 17 orang $(51,5 \%)$. Menurut status paritas, preeklampsia banyak terjadi pada multi paritas dengan 23 orang $(69,7 \%)$. Tenaga kesehatan yang terbanyak menangani preeklampsia pada penelitian ini ialah bidan 26 orang (82\%).

Tabel 2. Distribusi frekuensi kualitas asuhan antenatal

\begin{tabular}{clcc}
\hline No. & Kualitas Asuhan Antenatal & $\mathbf{f}$ & $\%$ \\
\hline 1. & Baik & 8 & 24,2 \\
2. & Kurang Baik & 25 & 75,6 \\
\hline & Total & 33 & 100 \\
\hline
\end{tabular}

Tabel 2 menunjukkan distribusi frekuensi kualitas asuhan antenatal yang didapat oleh pasien preeklampsia terbanyak kurang baik yaitu $75,8 \%$.

Tabel 3. Distribusi frekuensi kuantitas asuhan antenatal

\begin{tabular}{clcc}
\hline No. & Kuantitas Asuhan Antenatal & $\mathbf{f}$ & $\%$ \\
\hline 1. & $<7$ kali kunjungan & 28 & 85 \\
2. & $>7$ kali kunjungan & 5 & 15 \\
\hline & Total & 33 & 100 \\
\hline
\end{tabular}

Tabel 3 menunjukkan distribusi frekuensi kuantitas asuhan antenatal terbanyak pada $<7$ kali kunjungan yaitu 28 orang (85\%).
Tabel 4. Hubungan kualitas asuhan antenatal dan kejadian preeklampsia berdasarkan berat ringan

\begin{tabular}{|c|c|c|c|c|c|c|c|}
\hline \multirow{3}{*}{$\begin{array}{l}\text { Asuhan } \\
\text { Antenatal }\end{array}$} & \multicolumn{4}{|c|}{ Preeklampsia } & \multicolumn{2}{|c|}{ Total } & \multirow{3}{*}{ p } \\
\hline & \multicolumn{2}{|c|}{ Ringan } & \multicolumn{2}{|c|}{ Berat } & \multirow{2}{*}{ f } & \multirow{2}{*}{$\%$} & \\
\hline & $f$ & $\%$ & $f$ & $\%$ & & & \\
\hline Baik & 5 & 62,5 & 3 & 37,5 & 8 & 100 & \\
\hline Kurang & 7 & 28 & 18 & 72 & 25 & 100 & 106 \\
\hline \multicolumn{7}{|l|}{ Baik } & 0,100 \\
\hline Jumlah & 12 & 90,5 & 21 & 99,5 & 21 & 100 & \\
\hline
\end{tabular}

Tabel 4 menunjukkan bahwa kejadian preeklampsia terbanyak ialah preeklampsia berat dengan kualitas asuhan antenatal yang kurang baik. Hasil uji statistik Chi-Square Test dengan Fisher's Exact Test diperoleh nilai $\mathrm{P}=0,106(\mathrm{P}>0,05)$. Hal ini disimpulkan bahwa tidak terdapat pengaruh yang signifikan antara kualitas asuhan antenatal dengan kejadian preeklampsia berdasarkan berat ringannya.

\section{PEMBAHASAN}

Kejadian preeklampsia terbanyak ditemukan pada usia risiko rendah (25-35 tahun) sebanyak $51,5 \%$. Menurut kepustakaan, kejadian preeklampsia sering pada usia ekstrim yaitu $<20$ tahun dan $>35$ tahun, yang berhubungan dengan maladaptasi imunologi dan degeneratif vaskular. Kejadian preeklampsia bukan ditentukan oleh umur semata, tetapi banyak faktor risiko lain. ${ }^{1}$ Menurut Eruo dan Sibai (2007), faktor risiko preeklampsia meliputi riwayat preeklampsia, hipertensi kronis, penyakit ginjal, diabetes mellitus, trombofilia, obesitas, resistensi insulin, riwayat keluarga preeklampsia usia serta nullipara. ${ }^{9}$ Pada penelitian ini, factor risiko yang ditemukan meliputi riwayat preeklampsia sebelumnya sebanyak 7 orang $(21,2 \%)$, hipertensi kronis 3 orang (9\%), dan tidak ada yang memiliki riwayat penyakit jantung, ginjal dan diabetes mellitus. Faktor risiko lain seperti obesitas, resistensi insulin, dan trombofilia tidak diteliti sehingga kemungkinan kejadian preeklampsia pada penelitian ini terbanyak pada usia risiko rendah diakibatkan oleh faktor risiko lain tersebut.

Kejadian preeklampsia pada penelitian ini terbanyak ditemukan pada multipara $(69,7 \%)$, tetapi angka ini tidak meliputi angka keseluruhan kelahiran. Data keseluruhan kelahiran tidak dapat dikumpulkan 
karena kesalahan pada data rekammedis yang kurang lengkap.

Dibandingkan dengan multipara, nullipara lebih sering terjadi peeklampsia akibat pertama kali mengalami stress selama kehamilan. ${ }^{9}$ Disamping itu kejadian preeklampsia juga dapat disebabkan adanya underlying disease, seperti hipertensi kronis, diabetes mellitus dan penyakit ginjal. ${ }^{10}$

Asuhan antenatal terbanyak dilakukan pada penelitian ini oleh bidan 27 orang (82\%). Sebaiknya kehamilan dengan preeklampsia harus ditangani oleh dokter atau dokter spesialis, karena bidan hanya mempunyai kompetensi untuk kehamilan risiko rendah. ${ }^{11}$ Tingginya kejadian preeklampsia berat pada penelitian ini dapat disebabkan karena asuhan antenatal banyak dilakukan oleh bidan.

Asuhan antenatal yang berkualitas meliputi deteksi dini factor risiko pada kunjungan awal dan selanjutnya diikuti dengan pengamatan pada kunjungan berikutnya, sehingga dengan demikian dapat mencegah atau mengurangi keparahan suatu penyakit. Penyakit preeklampsia kejadiannya tidak dapat dicegah, tetapi dapat mencegah dari ringan menjadi berat. Deteksi dini faktor risiko preklampsia dapat ditentukan sehingga dapat dilakukan pengamatan yang berdampak terhadap menurunnya kejadian preeklampsia berat. Pada penelitian ini deteksi dini factor risiko preeklampsia yang dilakukan oleh tenaga kesehatan sudah baik (kisaran 51-79\%), tetapi tidak diikuti dengan pengamatan yang baik (kisaran 9-18\%) sehingga kejadian preeklampsia berat pada penelitian ini paling tinggi (64\%).

Pada penelitian ini, hasil uji statistik yang menghubungkan kualitas asuhan antenatal dengan berat ringannya preeklampsia didapatkan suatu hubungan yang tidak bermakna $(p=0.106, p>0.05)$, artinya kualitas asuhan antenatal tidak mempengaruhi kejadian preeklampsia berat. Kejadian preeklampsia berat bukan semata-mata dipengaruhi oleh kualitas asuhan antenatal yang kurang baik tetapi dapat juga dipengaruhi oleh pengetahuan, perilaku, sikap dan kepatuhan pasien sendiri. Pada penelitian ini pengetahuan, perilaku, sikap dan kepatuhan pasien tidak diteliti, sehingga ditemukan pada penelitian ini 5 orang yang mengalami kualitas asuhan antenatal baik terdapat preeklampsia berat sebanyak 3 orang.

Pada penelitian ini terdapat beberapa keterbatasan seperti tidak bisa menemukan alamat yang jelas karena data rekammedis di rumah sakit tidak lengkap, responden yang pindah rumah dan responden yang menolak mengikuti penelitian ini, sehingga responden penelitian menjadi sedikit.

\section{SIMPULAN}

Tidak terdapat hubungan antara asuhan antenatal dan preeklampsia.

\section{DAFTAR PUSTAKA}

1. Cunningham FG, Leveno KJ, Hauth JC, Bloom SL, Rouse DJ, Spong CY. Williams obstetric Ed isi ke23. New York: McGraw-hill Companies. 2010. hlm.42 - 754 .

2. Bagian Rekam Medis RSUP M. Djamil Padang. Laporan rekam medis tahun 2012. Padang. 2013.

3. Bagian Rekam Medis RSUP M. Djamil Padang. Laporan rekam medis tahun 2013. Padang. 2014.

4. Aksornphusitaphong $A$, Phupong V. Risk factors of early and late onset preeclampsia. Journal of Obstetrics and Gynaecology Research. 2013;39 (3):627 - 31.

5. Maryland Pregnancy Risk Assessment Monitoring System (PRAMS). Focus on quality of prenatal care. Baltimore: DHMH. 2007.hlm.1 - 4 .

6. Kementerian Kesehatan Republik Indonesia. Profil kesehatan Indonesia tahun 2012. Jakarta.2013; $120-22$

7. Greenbreg M. Prenatal Care. Dalam: Obstetric Evidence Based Guideline. London: Infoma Healthcare. 2007. hlm.3 - 13.

8. Liu CM, Chang SD, Cheng PJ. Relationship between prenatal care and maternal complications in women preeclampsia: implication for continuity and discontinuity of prenatal care. Tawainese Journal of Obstetric and Gynecology. 2012; 51(4): $576-82$ 
9. Eruo FU, Sibai BM. Hypertensive disease in pregnancy. Dalam: Clinical Obstetrics Fetus \& Mother Edisi ke-3. London: Blackwell Publishing.2007. hlm.683 - 99

10. Baktiyani SCW, Wahjudi I. Perbedaan efektivitas pemberian vitamin E $100 \mathrm{IU}$ dengan aspirin $81 \mathrm{mg}$ untuk pencegahan preeklampsia pada primigravida. JKB. 2005; 21:122

11. Queensland Centre for Mothers and Babies. Choosing your model of care. Brisbane.2012. hlm.1 - 28. 